lambs a year. Methods of producing superovulation are also known and, combined with the transplantation of the ova to other females, might enable us to multiply by a considerable factor the offspring of a valuable female. A first step has been taken towards the artificial production of tetraploids in mammals, and the doubling of hybrids cannot be considered technically out of the question. The hormonal control of sex-development may yet play a part in poultry and, perhaps, the dairy industries. Methods of separating female- from male-producing sperms have already had some success and may soon play a large part in the same two industries. The use of growth hormones for inducing giant forms, which might conceivably reproduce themselves true to type, is a possibility which may be realized within a few years.

The greatest technical advance which may be expected shortly is organization. The liaison between advanced institutes for practical and for theoretical biology is much less close in Great Britain than in many of the leading countries, such as Sweden, the U.S.S.R. and the United States. The return of many biologists from war-time tasks to biology will be a suitable time to introduce a well-considered re-organization of the whole scheme of biological teaching and practice, from the primary school to the university. Such a reorganization has been long over-due.

In dealing with industrial research and the universities, Dr. F. H. Boer inquired into the possibilities of promoting a beneficial exchange between science and industry. The application of new scientific discoveries and methods to industry and the consequent furtherance of research, necessitates a very close collaboration between men of science and all those concerned in the application of science, but in most countries collaboration between universities and industrial research laboratories is not close enough. The fear that industry will lose its secrets is one of the main factors, though in practice one finds that many of the so-called secrets are not secrets at all. In some large industrial research laboratories close cooperation between scientific workers and technicians exists, and the scientific workers are in touch with the universities.

Leaders of industrial research laboratories must be scientific men with highly developed technical minds and imaginations, and preferably some of them should hold a semi-official position at a university. Smaller industries should unite to establish and maintain sufficiently large research laboratories; there can be no place for small isolated research laboratories in the future, in Dr. Boer's opinion. The Government should endeavour to bring the smaller industries together, and to induce minorities to accept majority decisions. If industry realizes that its first task is to serve the community, then science will minister to industry unreservedly.

The technological advances of the last few decades, which, as Mr. Ritchie Calder pointed out, amount to a second industrial revolution, have made it incumbent upon scientific men to make certain that these advances are used to the benefit of humanity. The immediate task, in the words of Sir Harold Hartley, is to ensure that in the replanning of the world full use is made of the basic knowledge that science alone can provide, particularly in the fields of nutrition and energy, with all that they imply for the well-being of mankind.

\title{
SCIENCE AND WORLD PLANNING
}

SCIENCE and world planning was the subject of one of the sessions of the Conference on Science and World Order, and, in one form or another, planning was implicit in most of the papers presented at the Conference.

The need for planning was stressed by many speakers, and during the discussions on human needs and post-war relief the immediate aim of world planning was clearly stated to be the relief of human suffering and the provision of an adequate standard of life to human beings everywhere. Preparations with this immediate aim in view must be made now.

World planning is not a task to be lightly undertaken or one in which quick results can be expected.
As M. Maisky, the Soviet Ambassador, reminded the audience, it took the U.S.S.R. twenty years to reach its present advanced state of planned economy. In his view, the chances of replanning the world are years ahead. He characteristically claimed that the immediate plan for all of us is to win the War. Nevertheless world planning can and must be undertaken, provided we do not lose sight of our immediate objective, that of winning the War, and thus ensuring the opportunity to plan.

Some people object to planning because they fear that it would sacrifice the energizing force of competition. But, as Mr. Maurice Dobb, lecturer in economics in the University of Cambridge, 
pointed out, competition to-day is not what Adam Smith and the early economists extolled. We have now monopolistic competition, where the public interest tends to be thwarted rather than asserted, and the economically weak subordinated to the economically strong. This is the alternative with which we have to compare economic planning.

The post-war world will need larger economic units and more economic intercourse between nations. But it will need also the maintenance of full employment and the ending of exploitation of weak nations by strong. This synthesis demands a new regime of international planning. It implies the dominance of the social interest over the sectional, of the common good over individual profit.

The need for a new outlook was also stressed by Lord Hailey when dealing with colonial planning : ". . . a modern world which can combine to control the production of tea or rubber, or tin, or copper, in the interest of an investing public might well find the means of exhibiting a greater solidarity in dealing with issues vital to the welfare of Colonial peoples."

Mr. M. Wynants, of the Belgian Commission for the study of post-war problems, who spoke on town planning, was one of the few who attempted to look at the problem of world planning as a whole. $\mathrm{He}$ pointed out that the post-war world will be very different from the world we knew, and therefore we must face without delay the need for drastic solutions to the political, economic, social and moral problems. These are aspects of one and the same reality, and it is impossible to propose a solution in one of these fields without automatically bringing about corresponding reactions in the others.

Among the tasks mentioned by Mr. Wynants that can be satisfactorily accomplished only by international planning are: access to raw materials, development of backward areas, public works of an international character, human migration. A solution to these problems will be dependent upon a corresponding organization of political relations.

Town and country planning-according to Prof. William Holford, of the University of Liverpoolis chiefly concerned with the use of land for a variety of human purposes which may be broadly grouped as $(a)$ agriculture and forestry, $(b)$ development, including industry, $(c)$ recreation and $(d)$ transport.

The problems of agriculture were outlined by Sir John Russell, director of the Rothamsted Experimental Station. The agricultural systems of prescientific days, he stated, had two features in common: they aimed at providing complete subsistence for the community, and at conserving the land. The three-field or strip system common in Great Britain, round the Baltic, in northern India and elsewhere aimed further at an equitable distribution of good and bad land.

As practised in Europe, the strip system had the merit of permanence but was of low productiveness and had to be abolished. The U.S.S.R. adopted one method and Poland another, but a change was essential. In Great Britain the change to unified holdings was made before the scientific era, and technical improvements raised the output per man. higher than in any country in Europe, though the output per acre was less than in the smaller western countries of small holdings. In the new economic system introduced since the War, under which specified prices will be received and specified wages must be paid, and with the help of scientific methods, the indications are that high output per acre will be attained, as well as high output per man (see also Natuire, of October 18, p. 456$)$.

The dangers of deforestation were touched upon in a paper prepared by Lord Onslow, who made an appeal for the conservation of the wild life of the world. Within the last hundred years or so, several dozen species of animals of æsthetic, scientific and commercial value have been exterminated, and it is of the utmost importance to save others from a similar fate.

"Free play given to economic forces in the past has led to localization of a single industry in one district and has resulted in derelict areas and 'ghost towns' when that industry was depressed", stated Prof. P. Sargant Florence, of the University of Birmingham. Recent scientific progress has on the whole intensified the economic trend towards industrial concentration; if the social and socioeconomic criteria are accepted and dispersion of industry is adopted as a policy, hard thinking and fighting lies ahead for planners.

Dr. Othmar Ziegler, lately of the University of Prague, dealt with the transport problems of the Danube States, and estimated that if transport can contribute to raising the standard of life in southeastern Europe to one third or one half of that of western Europe it will furnish employment, through the expected increase in exports, to tens of thousands of workmen in western Europe.

The world's heat and power requirements was the subject of a paper by Sir Harold Hartley, who pleaded for a detailed consideration of the world's energy resources, their utilization and conservation, in the light of post-war schemes of reconstruction. If all the potential water resources were to be harnessed, the estimated energy would not exceed 30 per cent of the requirements, so that burning of fuel must continue to supply the greater part of the world's energy consumption until some other source, such as the direct utilization of the 
sun's radiation, has been made practicable upon a large scale.

Carbonization of raw coal and the use of electricity in a co-ordinated scheme, designed to secure maximum advantages from both, will help to solve the problem of smokeless cities and provide cheap energy needed in homes. Wider application of energy on farms, and in conditioned transport and storage, would increase productivity and accelerate processing. With the scientific knowledge we now possess it should be possible to plan with much greater certainty than in the past.

Dr. Ove N. Arup, a civil engineer from Copenhagen, inquired into the reasons why modern buildings lack many of the desirable qualities which modern science and technique have made possible : warm, sound-proof rooms, well ventilated and provided with labour-saving devices. The difficulty appears to lie in specialization, and Dr. Arup asked whether a "composite mind" could be created in the form of an organization that would achieve a well-balanced synthesis from the wealth of material available. There exist already teams which include architects, engineers, heating specialists, etc., but so long as such groups work for profit they may try to keep their experience secret or advocate materials and processes in which they have interests. An extension of the present research stations is needed, to carry out the checking up and classification of existing technical information, and the creation of planning organizations.

The nature of modern science demands not only planning and team work, stated Mr. D. P. Riley, of the University of Oxford, but also international planning and team work. To overcome the language difficulty a co-ordinated system of abstracting would be very valuable. More frequent international conferences should be held and their scope should be enlarged so that, with a modified organization of conference procedure, they may become valuable world-planning commissions.

Prof. Jacques Metadier, formerly professor of biological physics in the University of Poitiers, advocated the setting up of an international society for scientific - research, a kind of co-operative society to which everyone concerned in the exploitation of scientific discoveries would have to contribute a small percentage of their profits. Out of the resulting fund payments would be made to scientific workers whose researches had been economically exploited, and, in addition, research scholarships would be created and pensions would be made available to research workers over a given age, even though their labours may not have had practical applications.

Turning from visions of what the future might bring, to research now being carried out relating to planning and to post-war reconstruction, Prof.
Alvin H. Hansen, of Harvard University, gave an outline of what is being done in the United States. For the last eight years the National Resources Planning Board has been engaged in studies relating to the natural, human, scientific and economic resources of the nation. Some of its activities in connexion with social welfare have already been noted (see p. 455). In addition, the Board is required to maintain a six-year programme of Federal Public Works.

In 1934 the Board sponsored a survey of the extent of soil erosion, which led to the establishment of the Federal Soil Conservation Service with authority to make surveys, conduct research, establish demonstrations and educate the public about soil conservation. In 1936 the new Agricultural Adjustment Act combined the dual purpose of soil conservation and agricultural production, and the Flood Control Act charged the Department of Agriculture with. responsibility for watershed treatment.

One of the most significant achievements of the United States Government during the past ten years has been the redevelopment of the Tennessee Valley, with an area nearly as large as Great Britain. The large-scale planning carried out by the Tennessee Valley Authority was described by Prof. L. Gulick (see p. 388). Planning, said Prof. Gulick, is not only compatible with a democratic system of multiple parties, free elections, free criticism, free discussion, free enterprise and private capitalism, but it is essential in releasing the energies of freely co-operating individuals and governmental and private corporations in fulfilment of plans and objectives.

Mr. Hugh P. Vowles, on the other hand, who has made a study of large-scale electrification in several countries, considers that scientific planning upon a comprehensive scale is incompatible with private capitalism. There can be no co-ordinated development of power and associated resources, since one authority would plan electrification and another gas supply without pausing to consider whether they fit together, or with other associated activities. In the Soviet Union, he claimed, co-ordinated planning covers all aspects of exploitation of power and material resources, with the public welfare kept steadily in view.

This ends the series of summaries of deliberations of the Conference. In this, and in the previous five reviews, an attempt has been made to bring together pronouncements bearing upon specific subjects, so as to form a consecutive whole. Unfortunately, the contributions considered, though generally good in their particular field, frequently bore little relation to one another ; they will serve excellently, however, as material for a future conference on world planning. 